\title{
Microangiopatía trombótica e injuria renal aguda en el primer trimestre de embarazo
}

\author{
Thrombotic microangiopathy and acute kidney injury in \\ the first trimester of pregnancy
}

Iván González-Hoyos', Fernando Lombi', Mariano Forrester', Vanesa Pomeranz', Romina Iriarte', Tatiana Rengel', Matías Paulero', Raquel Gianserra', Iván González², Alejandro lotti², Hernán Trimarchi'

\section{RESUMEN}

La microangiopatía trombótica acompañada de injuria renal aguda (IRA) en el embarazo es un desafío diagnóstico y terapéutico. Presentamos el caso clínico de una mujer de 29 años de edad cursando el primer trimestre del embarazo, que presentó IRA, anemia hemolítica microangiopática y plaquetopenia, que se correlacionaron con hallazgos compatibles con microangiopatía trombótica (MAT) severa en la punción biopsia renal. Se decidió realizar un estudio genético para las mutaciones del complemento evidenciándose deleción heterocigota de los genes CFHR3/CFHRI y anticuerpos anti factor $\mathrm{H}$ del complemento positivos, haciéndose el diagnóstico de síndrome urémico hemolítico atípico (SUHa). El tratamiento con plasmaféresis y recambio plasmático permitió una evolución clínica favorable de la paciente y estabilización de la función renal.

Palabras clave: microangiopatía trombótica, insuficiencia renal aguda, embarazo.

\begin{abstract}
Microangiopathic thrombopathy (TMA) and acute kidney injury (AKI) during pregnancy is a diagnostic and therapeutic challenge. We present the case of a 29 year old woman undergoing the first trimester of her pregnancy who developed $\mathrm{AKI}$, microangiopathic hemolytic anemia and thrombocytopenia, which correlated with kidney biopsy findings consistent with severe thrombotic microangiopathy. A genetic test for mutations of the complement system was performed, informing heterozygous deletion of the CFHR3/CFHRI genes and positive antibodies against complement factor $\mathrm{H}$. The diagnosis of atypical hemolytic uremic syndrome (aHUS) was made. The patient was started on plasmapheresis with plasma exchange, leading to a rapid improvement in the clinical outcome of the patient and stabilization of kidney function.
\end{abstract}

Keywords: microangiopathic thrombopathy, acute kidney injury, pregnancy.

\section{INTRODUCCIÓN}

El abordaje de los cuadros de microangiopatía trombótica (MAT) durante el primer trimestre de embarazo constituye un desafío, en especial aquellos que cursan con injuria renal aguda (IRA), dadas sus implicancias en términos de morbimortalidad materno-fetal. Una de las causas más frecuentes de estos cuadros se encuentra representada por el síndrome urémico hemolítico atípico (SUHa) puesto que el embarazo constituye un factor predisponente del mismo. Con el advenimiento del concepto de medicina de precisión, el diagnós-

I. Servicio de Nefrología, Hospital Británico de Buenos Aires.

2. Servicio de Anatomía Patológica, Hospital Británico de Buenos Aires.

Correspondencia: Dr Hernán Trimarchi. Hospital Británico. Perdriel 74 (I280) Buenos Aires, Argentina. Tel 54I I 43096400 Fax 54 I I

43043393.Email: htrimarchi@hotmail.com

Los autores declaran no poseer conflictos de intereses. tico no debe limitarse solo al cuadro clínico sino que se debe ir más allá y buscar el sustento genómico que justifica la presentación del cuadro, con el objetivo de mejorar intervenciones futuras.

\section{CASO CLÍNICO}

Se presenta el caso de una mujer de 29 años de edad con antecedentes de: obesidad mórbida, lupus eritematoso sistémico (LES) y síndrome de anticuerpos antifosfolipídicos (SAF) diagnosticados desde los 18 años de edad (asociado a 3 abortos en los años previos). Niega consumo de tabaco, alcohol o abuso de sustancias. Medicación actual: hidroxicloroquina y acenocumarol.

Cursando 8va semana de embarazo es admitida en la unidad de cuidados intensivos del Hospital Británico debido a dolor torácico. Al examen físico presentaba una tensión arterial (TA) 130/82, sin edemas. Laboratorio al ingreso: hematocrito $36.4 \%$, hemoglobina $11 \mathrm{~g} / \mathrm{dl}$, glóbulos blancos $6.500 \mathrm{~mm}^{3}$, recuento de plaquetas $150.000 \mathrm{~mm}^{3}$, sodio $137 \mathrm{mEq} / 1$, potasio $3.7 \mathrm{mEq} / \mathrm{l}$, urea $20 \mathrm{mg} / \mathrm{dl}$, creatinina sérica $0.78 \mathrm{mg} / \mathrm{dl}$, glucemia $108 \mathrm{mg} / \mathrm{dl}$, ALT $28 \mathrm{U} / \mathrm{l}$, AST $45 \mathrm{U} / \mathrm{l}$, fosfatasa alcalina $114 \mathrm{U} / \mathrm{l}$, colesterol total 


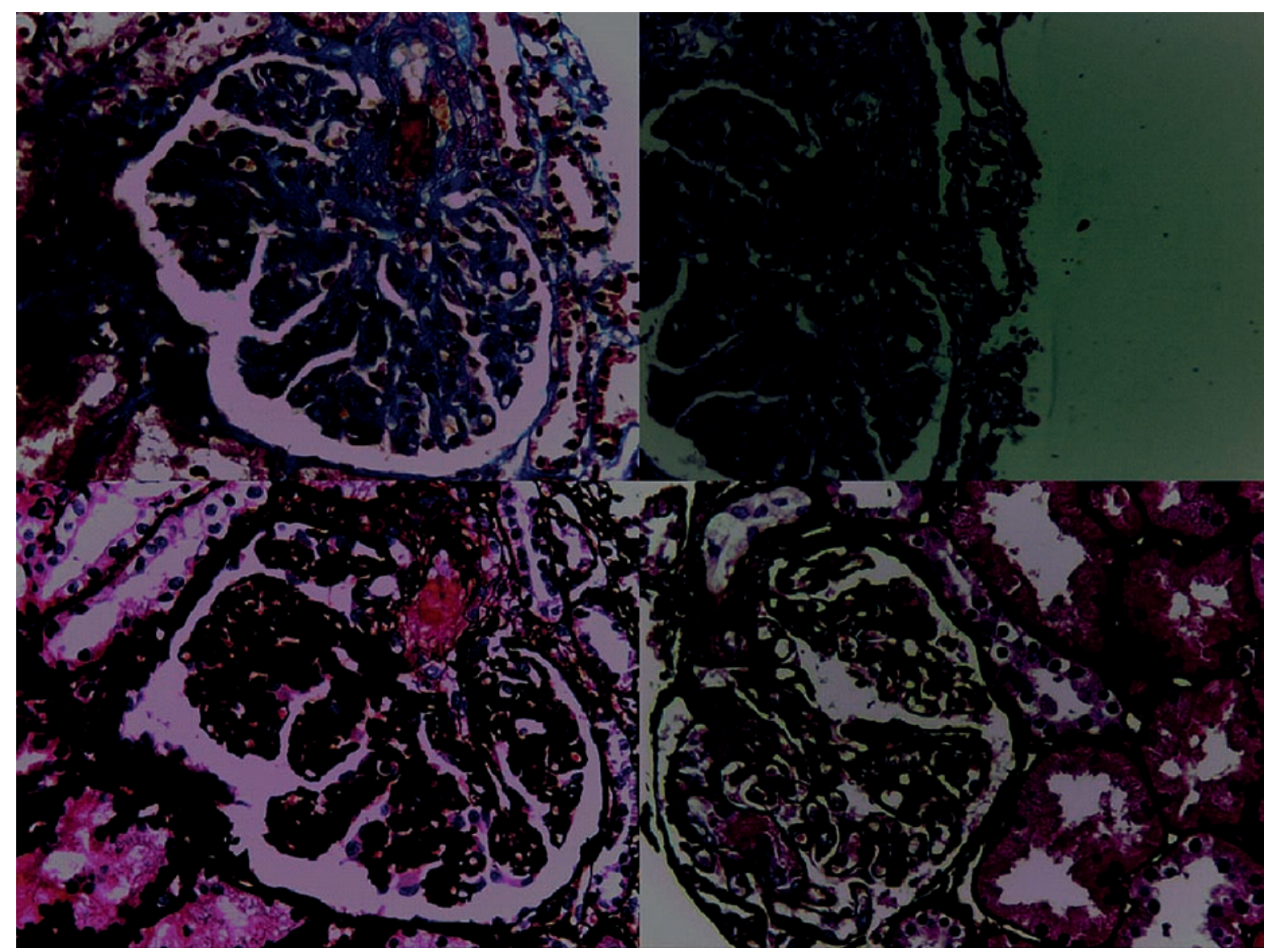

Figura I. Trombos en arteriola aferente y capilares glomerulares. A) Tricrómico de Masson 400X; B) PAS 400X; C) Metenamina plata 400X y D) Metenamina plata 400X.

$146 \mathrm{mg} / \mathrm{dl}$, albúmina $3.6 \mathrm{~g} / \mathrm{dl}$, LDH $186 \mathrm{U} / \mathrm{l}$, haptoglobina $212 \mathrm{mg} / \mathrm{dl}$ (valor normal: 32-197 mg/dl). La paciente fue evaluada por el Servicio de Cardiología desestimándose patología coronaria aguda. Por molestias abdominales, la paciente permanece internada con el fin de completar estudios. No obstante, a las 48 hs de su admisión evoluciona con hipertensión arterial con registros de TA 156/92 mmHg e IRA. La diuresis estaba conservada. No presentaba estigmas clínicos de recaída del lupus. En el laboratorio presentaba caída del hematocrito $28.6 \%$, hemoglobina $8.8 \mathrm{~g} / \mathrm{dl}$ y del recuento de plaquetas $25.000 \mathrm{~mm}^{3}$ asociado a ascenso de la creatinina sérica a $1.39 \mathrm{mg} / \mathrm{dl}$. Por sospecha de AHM se amplió la evaluación del laboratorio hallándose una $\mathrm{LDH}$ $728 \mathrm{U} / \mathrm{l}$, nivel de C3 $68 \mathrm{mg} / \mathrm{dl}$, nivel de C4 $6.6 \mathrm{mg} / \mathrm{dl}$, haptoglobina $<3 \mathrm{mg} / \mathrm{dl}$, proteína $\mathrm{C}$ reactiva $0.41 \mathrm{mg}$ / dl, anti-DNA positivo. En el análisis de orina: $\mathrm{pH}$ 6.5, densidad 1.005, proteínas $0.25 \mathrm{~g} / \mathrm{l}$, glóbulos rojos 10 20 por campo; de los cuales $72 \%$ eran dismórficos con $4 \%$ de acantocitos. Proteinuria de 24 horas $0.79 \mathrm{~g} /$ día. Anticuerpos anticardiolipinas tanto IgM como IgG se encontraban dentro de límites normales, inhibidor lúpico positivo; prueba de Coombs directa $+/+++$, antiRho, anti-La, p-ANCA, c-ANCA, serologías para HIV, HBV y HCV fueron negativas. RIN: 2.2. El extendido de sangre periférica no demostró la presencia de esquis- tocitos. Determinación de toxina para Escherichia coli 0157:H7 negativa. Las ecografías y Doppler abdominal, renal y fetal se encontraban dentro de límites normales. Se decidió iniciar labetalol y alfametildopa con normalización de la tensión arterial.

Dado el cuadro que presentaba la paciente cursando 8va semana de embarazo, conformado por AHM, HTA, hematuria-proteinuria e IRA, se barajaron como hipótesis diagnósticas un cuadro de microangiopatía trombótica, LES o SAF. Se inició tratamiento empírico con tres pulsos de $1 \mathrm{~g} /$ día de metilprednisolona, rotándose posteriormente a $60 \mathrm{mg} /$ día de meprednisona más azatioprina 100 mg/día. Asimismo, se realizó una punción biopsia renal guiada por ecografía que evidenció cambios compatibles con microangiopatía trombótica (Figura 1). Se dosó una actividad de ADAMTS 13 de $58 \%$ (valor normal igual o mayor a $70 \%$ ) baja actividad. Con diagnóstico de microangiopatía trombótica secundario a un probable cuadro de SUHa, se decidió iniciar tratamiento con plasmaféresis objetivándose mejoría del cuadro clínico de la paciente y estabilización de los niveles de creatinina sérica.

Con el fin de evitar intercurrencias futuras, se solicitó estudio genético para mutaciones del complemento, que mostró deleción heterocigota de los genes CFHR3/CFHRI y anticuerpos anti factor $\mathrm{H}$ del complemento positivos. 


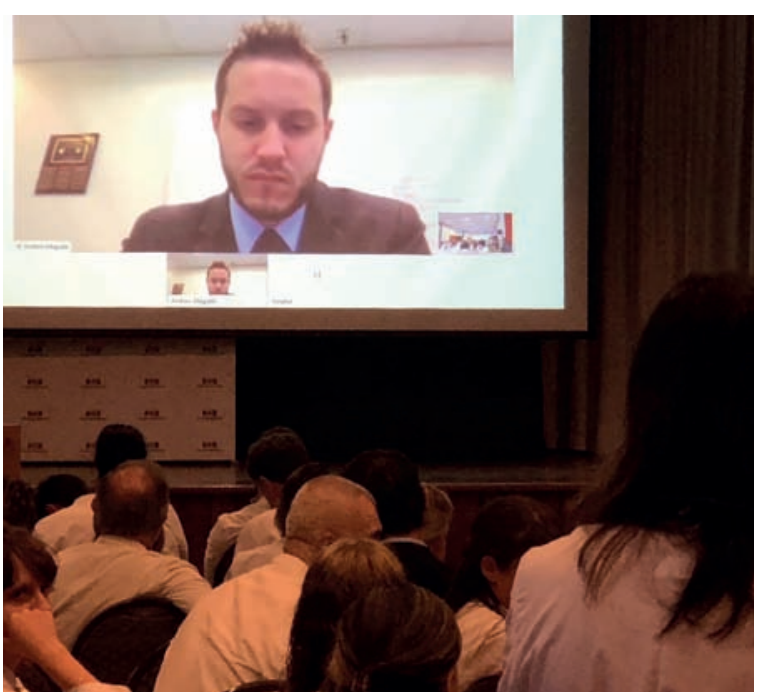

Figura 2. Videoteleconferencia con el Dr.Andrew Allegretti, del Servicio de Nefrología del Massachussets General Hospital de Boston, USA.

La presentación del caso se hizo en simultáneo por video teleconferencia con el Dr. Andrew Allegretti del Servicio de Nefrología del Massachussets General Hospital de Boston, USA (Figura 2), ante la presencia de la audiencia (Figura 3).

\section{DISCUSIÓN}

El sistema del complemento constituye uno de los principales componentes de la inmunidad innata, con la consecuente capacidad para identificar y eliminar material extraño y propio alterado así como para promover una respuesta inflamatoria e inmune apropiada. En condiciones normales, cerca de la mitad de las proteínas involucradas en el sistema del complemento se dedican a ejercer un control estricto de las respuestas proinflamatorias del mismo con el fin de evitar el daño sobre el huésped ${ }^{1,2}$.

En el SUHa, la respuesta alterada y descontrolada de la vía alterna de complemento constituye la base fisiopatológica de la enfermedad y es el responsable de la mayoría de los síndromes urémicos hemolíticos no mediados por la E. coli productora de toxina Shiga ${ }^{3}$.

La presentación del SUHa (anemia hemolítica microangiopática, trombocitopenia y microangiopatía trombótica) requiere la presencia de la susceptibilidad genética previa por alguna mutación en las proteínas reguladoras o efectoras de la vía alterna o bien por la presencia de anticuerpos contra alguno de estos componentes reguladores. Hasta el momento, las mutaciones más conocidas en la vía alterna son: cofactor $\mathrm{H}$ (CFH: $15-20 \%$ de los casos), cofactor I (CFI: 3-6\% de los casos), C3 (4-6\% de los casos), cofactor de proteínas de membrana (6-10\%), gen de la trombomodulina (THBD 2\% de los casos), o bien, autoanticuerpos antiFH del complemento (6-10\% de los casos) $)^{4,5}$. La expresión de la enfermedad es entonces consecuencia de si-

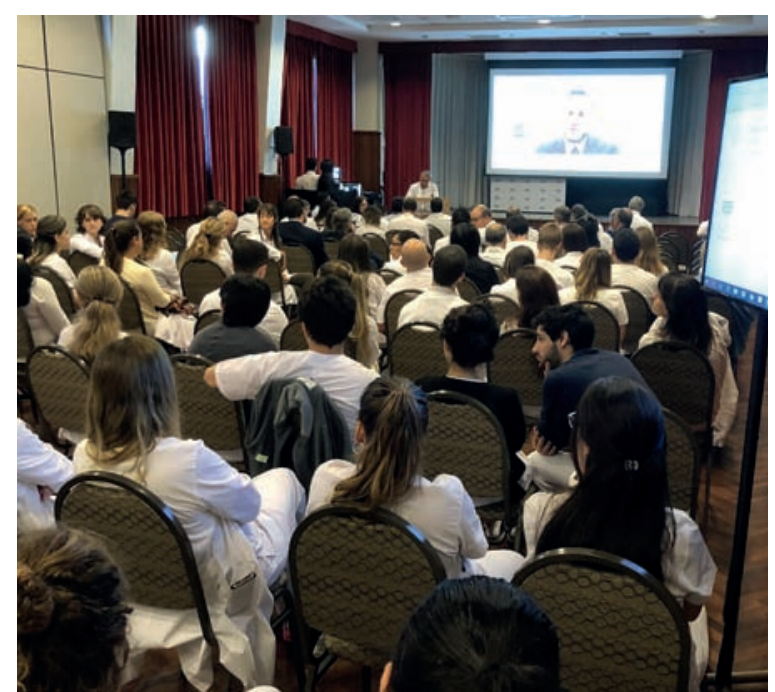

Figura 3. Audiencia en el salón Ravenscroft bajo la coordinación del Dr.Trimarchi.

tuaciones que actúan como amplificadores de la vía alterna del complemento en los pacientes susceptibles: infecciones, enfermedades autoinmunes como el lupus eritematoso sistémico, el síndrome por anticuerpos antifosfolipídicos, trasplantes, drogas inmunosupresoras y el embarazo son algunos de las situaciones coexistentes que podrían precipitar el cuadro ${ }^{5,6}$.

La actividad crónica no controlada del mismo puede resultar en daño endotelial continuo y riesgo permanente de MAT como consecuencia del ensamble de complejos C5b-9, activación constante de la vía alterna del complemento y fenómenos protrombóticos por denudación endotelial por daño vascular directo. Esto conduce entonces a un círculo vicioso crónico de activación endotelial, amplificación del complemento y lesión endotelial permanente con la posterior liberación de proteínas protrombóticas, activación plaquetaria y leucocitaria con la posterior formación de trombos en los pequeños vasos e isquemia de los circuitos involucrados, de los cuales el lecho renal es particularmente susceptible 5 .

La deleción homocigota de un fragmento genómico de $84 \mathrm{~kb}$ en el cromosoma humano 1 que abarca los genes de la proteína 1 relacionada al factor $\mathrm{H}$ del complemento (CFHR1) y de la proteína 3 (CFHR3) representa un factor de riesgo para el síndrome urémico hemolítico (SUH). El CFHR1 actuaría como inhibidor de la vía del complemento que bloquea la actividad de la C5 convertasa e interfiere con el depósito de superficie C5b y la formación del complejo de ataque a membranas (MAC). Esta actividad es distinta de la del factor $\mathrm{H}$ del complemento, dado que tanto el factor $\mathrm{H}$ como la CFHR1 controlarían la activación del complemento de una manera secuencial. Ambas proteínas se unirían a los mismos sitios en las superficies celulares y el aumento de la actividad de CFHR1 se generaría a expensas de la función mediada por factor $\mathrm{H}$ del complemento (CFH): la inhibición de la C3 convertasa. En el SUHa, 
la ausencia de CFHR1 puede dar como resultado una diminución de la inhibición de la formación del complejo terminal y una reducción de la protección de las células endoteliales tras el ataque del complemento ${ }^{6,7}$.

Aunque el defecto genético del factor $\mathrm{H}$ del complemento $(\mathrm{CFH})$ constituye una causa común del SHUa, también se sabe que el desarrollo de autoanticuerpos frente al $\mathrm{CFH}$ (CFH-Ab) es una causa adquirida de SHUa. Existe una correlación entre el desarrollo de CFH-Ab y la deficiencia de las proteínas relacionadas con CFH, CFHR1 y CFHR3 $3^{6,8}$.

En un estudio se midieron los perfiles plasmáticos del complemento y se realizaron análisis genéticos de los genes $C F H, C F I, M C P, C F H R I$ y CFHR 3 en tres pacientes de sexo femenino diagnosticadas con SHUa con anticuerpos anti-FH positivos. Durante los estadios agudos en los 3 pacientes se hallaron bajos títulos de C3, normales o bajos de CFH y altos títulos de anticuerpos contra el CFH. Todos los pacientes también mostraron una deficiencia completa de CFHR1 en plasma y deleción genómica homocigótica de CFHR1/ CFHR3, pero ninguna tenía mutaciones de $C F H$, CFI o $M C P$. Estos pacientes presentaron un nuevo subgrupo de SHUa caracterizado por una combinación de factores genéticos (una eliminación homocigótica de CFHR1 / CFHR3) y adquiridos (desarrollo de CFH-
Ab). Estos hallazgos justificarían la necesidad de detectar los CFH-Ab y la deficiencia de CFHR1/CFHR3 en las pruebas de diagnóstico para pacientes con $\mathrm{SHUa}^{6,9}$. La base del tratamiento descansaría en plasmaféresis y terapia inmunosupresora adicional como con el eculizumab $^{8}$.

\section{CONCLUSIONES}

La IRA en el primer trimestre del embarazo suele ser ocasionada por entidades más prevalentes como pielonefritis/sepsis e hiperemesis gravídica. La MAT como cuadro de presentación de la IRA, es por lo general más prevalente en el tercer trimestre del embarazo. El presente caso constituye un desafío diagnóstico que debe pensarse ante la existencia de anemia hemolítica microangiopática, en pacientes con hipertensión arterial y enfermedades o situaciones clínicas capaces de amplificar la vía alterna del complemento y ocasionar eventualmente IRA. El mayor conocimiento y entendimiento de las bases fisiopatológicas del SUHa, considerada hasta el día de hoy como una entidad rara, hace que su abordaje diagnóstico sea más ordenado, claro y con opciones terapéuticas según la necesidad y gravedad del cuadro clínico subyacente en consonancia con los postulados del concepto de medicina de precisión.

\section{BIBLIOGRAFÍA}

I. Holers VM. Complement and its receptors: new insights into human disease. Annu Rev Immunol 2014;32:433--59.

2. Mathern DR, Heeger PS. Molecules Great and Small:The Complement System. Clin J Am SocNephrol 20 I 5; I0(9): I 636-50

3. Noris M, Caprioli J, Bresin E, et al.Relative role of genetic complement abnormalities in sporadic and familial aHUS and their impact on clinical phenotype. Clin JAm SocNephrol 20 I0;5( I 0): I 844-59.

4. Goodship TH, Cook HT, Fakhouri F, et al. Conference Participants. Atypical hemolytic uremic syndrome and C3 glomerulopathy: conclusions from a "Kidney Disease: Improving Global Outcomes" (KDIGO) Controversies Conference. Kidney Int. 2017:91 (3):539-5।.

5. Heinen S, Hartmann A, Lauer $\mathrm{N}$ et al. Factor H-related protein I

(CFHRinhibits complement C5 convertase activityand terminal complex formation. Blood 2009; I | 4( I 2):2439-47.

6. Lee $\mathrm{BH}, \mathrm{Kwak} \mathrm{SH}$, Shin Jl, et al. Atypical hemolytic uremic syndrome associated with complement factor $\mathrm{H}$ autoantibodies and CFHRI/CFHR3 deficiency.Pediatr Res2009;66(3):336-40.

7. Noris M, Remuzzi G.Atypical hemolytic-uremic syndrome. N Eng| J Med 2009;36 I (17): I676-87.

8. Kavanagh D, Richards A, Fremeaux-Bacchi V, et al. Screening for complement system abnormalities in patients with atypical hemolytic uremic syndrome. Clin J Am SocNephrol 2007;2(3):591-6.

9. Huerta A,Arjona E, Portoles J, et al.A retrospective study of pregnancy-associated atypical hemolytic uremic syndrome. Kidney Int 2018:93(2):450-59. 